\title{
A magnetic resonance study of early schizophrenia
}

\author{
EC JOHNSTONE,* TJ CROW,* JF MACMILLAN,* DGC OWENS,* GM BYDDER, $\dagger$ \\ RE STEINER†
}

From the Division of Psychiatry, ${ }^{*}$ Clincal Research Centre, Harrow, Middlesex, and the Department of Diagnostic Radiology, Royal Postgraduate Medical School, $\uparrow$ Hammersmith Hospital, London, UK

SUMMARY Patients with untreated first schizophrenic episodes and others who had made varying degrees of recovery from such episodes were blindly compared with normal volunteers in terms of the periventricular appearances on spin echo magnetic resonance scans. Significant differences were not found.

The first computed tomography scan study of schizophrenia ${ }^{1}$ revealed that some patients with chronic illnesses have structural changes in the brain as indicated by increased ventricular size. These CT findings have been generally confirmed by other workers, ${ }^{23}$ and they are consistent with earlier findings in pneumoencephalographic studies. ${ }^{4-6}$ The presumption that the radiological appearances reflect structural changes in the brain is supported by a recent post-mortem sudy in which the brain weight was found to be reduced and lateral ventricular (particularly temporal horn) volume increased in patients with schizophrenia by comparison with affective disorder. ${ }^{7}$ Two questions are outstanding.

1 Is there evidence of a pathological process in the brain substance which could account for the cell loss or shrinkage presumed to underlie the structural change?

2 What is the temporal relationship between structural changes and the onset of schizophrenia and the development of the defect state?

The recent application of magnetic resonance to cerebral imaging has offered new possibilities in the approach to these problems. Using inversionrecovery images grey and white matter can be contrasted to display anatomical detail which is not defined with CT. Oedema and inflammatory changes are well visualised with MR imaging. ${ }^{8}$ It is plausible that the ventricular enlargement found in schizophrenic patients might result from a pathological process in the periventricular area in the acute phase. Such a process might be seen with MRI. In this study magnetic resonance imaging was used to examine the periventricular area in patients with early schizophrenia and in controls. The comparison between

Address for reprint requests: Dr EC Johnstone, Clinical Research Centre, Watford Rd, Harrow, Middx HA1 3UJ, UK. normal controls and patients with untreated first episodes of schizophrenia is of obvious interest. If $\vec{\omega}$ differences were found it would be important to know 2 if the appearances persist beyond the first episode and whether or not such persistence was associated with? outcome. Patients with varying outcome following $\vec{c}$ first episodes of schizophrenia were therefore included in the study.

\section{Method}

At the time of the study an investigation of the outcome first schizophrenic episodes was in progress. ${ }^{9}$ It was possibte to select sub-samples of patients who had made varyiris degrees of recovery following neuroleptic treatment of such. episodes. For the purposes of the present imaging stum $\overrightarrow{0}$ these patients, whose diagnosis had been confirmed by $\infty$ Present State Examination ${ }^{10}$ during the initial admission, were categorised on the basis of assessments made during their psychotic episode and at subsequent outpatient followup as (a) patients of abnormal and asocial premorbid personality with a poor social and clinical outcome, (b) patients of normal premorbid personality with a poor social and clin- $\frac{\mathrm{O}}{\mathbb{1}}$ ical outcome, (c) patients of normal premorbid personality with a successful clinical and social outcome.

Relatively few female patients from this sample were 3 available and the study was therefore restricted to male sub- $\bar{Z}$ jects. Myelination may be seen on MR images, and has been shown to be still occurring in the second decade. In view of the youth of the patients in the first episodes of schizophrenia study (median age of males $24 \cdot 1$ years $^{11}$ ) control 0 subjects were closely matched for age with the patients in $\frac{0}{3}$ outcome groups (a), (b) and (c). Controls were normal male volunteers with no personal or family history of psychiatric 8 illness and no history of alcohol or drug abuse. The neuro- 3 leptic-free group studied consisted of all cases of acute 0 untreated first episode schizophrenia admitted to Northwick Park Hospital under the care of the participating clinicians $\frac{D}{O}$ during the period of the study. The patients $(10$ males, 1 ․ female) had the diagnosis of schizophrenia confirmed $\bar{N}$ shortly following admission by use of the Present State 
Table The characteristics of the sample

\begin{tabular}{|c|c|c|c|c|c|}
\hline & $\begin{array}{l}\text { Poor outcome } \\
\text { never normal }\end{array}$ & $\begin{array}{l}\text { Poor outcome } \\
\text { once normal }\end{array}$ & $\begin{array}{l}\text { Good outcome } \\
\text { once normal }\end{array}$ & $\begin{array}{l}\text { Neuroleptic free* } \\
\text { lst schiz episode }\end{array}$ & Normal controls \\
\hline $\begin{array}{l}\text { Number } \\
\text { Sex } \\
\text { Age } \pm \text { SD } \\
\text { Positive symptoms Krawiecka scale } \\
\text { Negative symptoms Krawiecka scale } \\
\text { Social liability/self care }\end{array}$ & 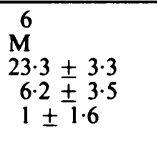 & $\begin{array}{l}\mathbf{4} \\
\mathbf{M} \\
22.7 \pm 3.5 \\
4.5 \pm 3.7 \\
1.5 \pm 1.9\end{array}$ & $\begin{array}{l}\stackrel{6}{\mathbf{M}} \\
23 \pm 2 \cdot 1 \\
2 \cdot 8 \pm 5 \cdot 2 \\
0\end{array}$ & $\begin{array}{l}11 \\
10 \mathrm{M} ; 1 \mathrm{~F} \\
21 \cdot 8 \pm 3 \cdot 6 \\
-\end{array}$ & $\begin{array}{l}12 \\
M \\
24 \cdot 7 \pm 3 \\
-\end{array}$ \\
\hline (higher score $=$ worse) & $2 \cdot 7 \pm 1$ & $2 \cdot 3 \pm 1 \cdot 2$ & 0 & - & - \\
\hline
\end{tabular}

*One exception: see text.

Examination $^{10}$ and MRI was conducted before commencement of neuroleptic medication.

On the day that the MR scan was conducted the mental states of the patients in outcome groups (a) and (c) were assessed using the scale devised by Krawiecka $e t a^{12}$ and their social functioning on the selfcare and social liability parts of the rating scale devised by Cooper ${ }^{13}$ Because of the local employment situation the part of the scale relating to unemployment was omitted although in fact only patients in the good outcome group were employed.

Transverse inversion-recovery and spin echo images were obtained in the low ventricular region of the brain using an MRI scanner which has been described previously. ${ }^{14} \mathrm{~A}$ series of slices was obtained in each case. Abnormal areas were identified by increased signal intensity on the spin echo scans and decreased signal intensity on the inversion recovery scans.

\section{Results}

Satisfactory scans were obtained from twenty seven schizophrenic patients and twelve controls. A twentyeighth patient whose clinical presentation was of an acute first episode of schizophrenia was excluded from further assessment as his MR scan showed appearances consistent with a hypothalmic lesion. The characteristics of the sample are shown in the table.

One first episode schizophrenic patient with an identical twin was scanned when co-operative after some weeks of neuroleptic treatment. His twin was psychiatrically normal and was also scanned. The well twin does not appear in the table.
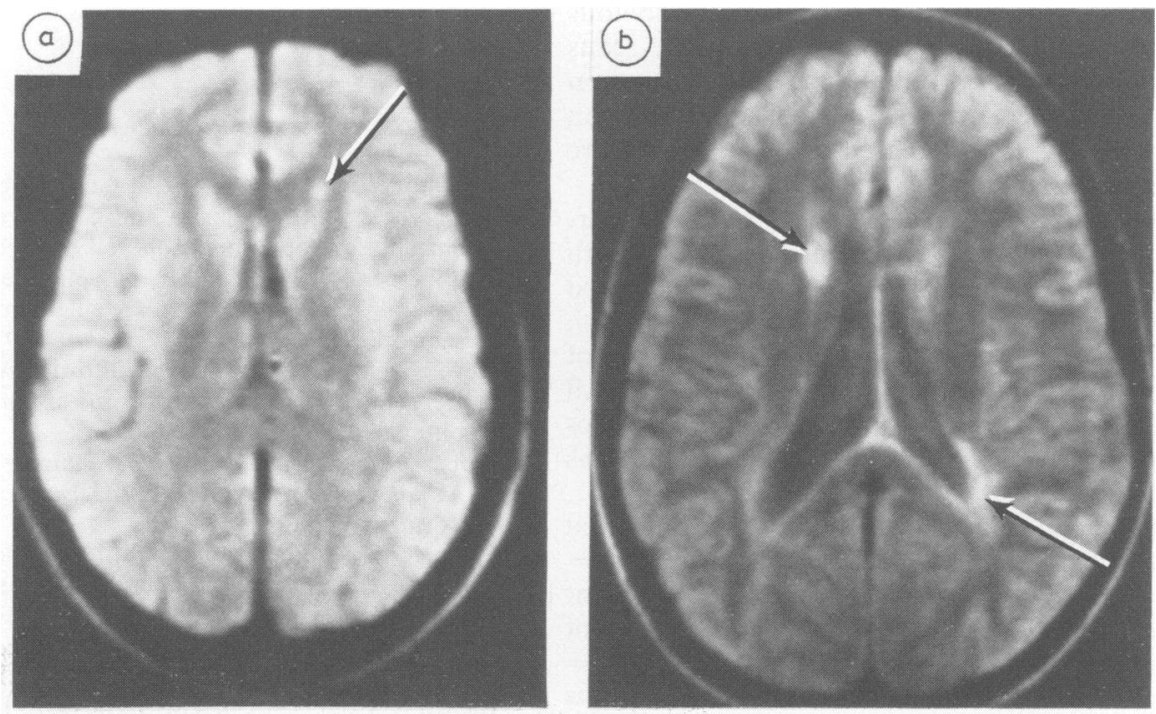

Fig 1 (a) Scan with normal appearance (b) scan with increased signal intensity at angles of ventricles. 


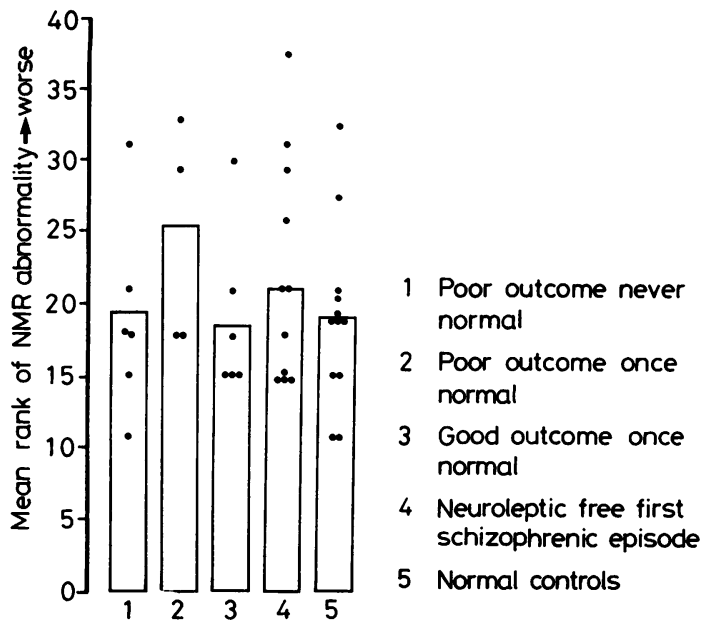

Fig 2 Patients in all schizophrenic groups and controls in terms of ranking of signal intensity at the angles of ventricles.

The scans were reviewed blindly by the radiologists involved (GB, RS) who considered that some of the spin echo scans showed an unusual increase in signal intensity at the angles of the ventricles. Decreased signal intensity in the periventricular area was seen on the inversion recovery scans. Such appearances could be consistent with an alteration of the consistency of the brain in the periventricular area. These investigators demonstrated these findings and the normal appearances of this area to the clinicians involved (TJC, ECJ or DGCO). As the increased signal intensity on the spin echo scans is more obvious and as the decrease in the inversion recovery scans can be confused with partial volume effects attention was confined to the former. A normal spin echo scan and one showing the increased signal intensity are illustrated in fig 1 .

All five investigators each blindly rated the appearance in every subject as normal, possibly with increased signal intensity, definitely with increased signal intensity. The inter-rater reliability was high (Kendal's W $=0.53, p<0.00001$ ) and exclusion of each of the raters in turn had no significant effect. All five ratings were therefore summated and the cases were ranked in terms of this sum. The results in terms of the ranking are shown in fig 2.

No significant differences were demonstrated between the five groups (Kruskal-Wallis test, $\mathrm{Chi}^{2}=$ $5.03, \mathrm{df}=4, \mathrm{p}=0.28$ ) and there was no significant difference between the controls and the total group of schizophrenic patients. (Mann-Whitney $U$ test; $\mathbf{Z}=$ $0 \cdot 65, \mathrm{p}>0.05$ ). Individuals with high and low ranks were found in all five groups (fig 2). The results were also calculated using the radiologists ratings alone
Johnstone, Crow, Macmillan, Owens, Bydder, Steiner

but again no significant differences were found. The mean ranks were as follows: poor outcome never normal 17.8; poor outcome once normal 27.8 ; good outcome once normal 15.5; first episode schizophrenics 23.3; controls 17.7. The well twin is not included in any of these comparisons but both twins achieved a similarly high rank on the assessment.

\section{Conclusion}

In this MRI study of patients with early schizophrenia and controls an increase in signal intensity on spin echo images at the angles of the ventricles was found in a number of subjects. The inter-rater reliability in assessing this appearance was high but blind comparison of patients and controls showed no differences. These results indicate that the appearance of increased signal intensity at the angles of the ventricles on spin echo images using magnetic resonance is unrelated to the diagnosis of schizophrenia and is not relevant to the nature of the outcome following first schizophrenia episodes. Similar appearances have been described in some normal volunteers, ${ }^{15}$ as well as in elderly patients in association with vascular disease. ${ }^{16}$ The use of this technique afforded no evidence that there was a pathological process in the periD ventricular area in these cases of early schizophrenia

The authors are grateful to the patients and control for participating in this study and to the responsible $T$ consultants for their help. The study was conducted 음 under the auspices of the Ethical Committee of Northwick Park Hospital and was carried out accord들. ing to its rules.

\section{References}

${ }^{1}$ Johnstone EC, Crow TJ, Frith CD, Husband J, Kreel L. Cerebral ventricular size and cognitive impairment in chronic schizophrenia. Lancet 1976;ii:924-6.

${ }^{2}$ Weinberger DR, Torrey EF, Neophytides N, Wyatt RJ. Lateral cerebral ventricular enlargement in chronic schizophrenia. Arch Gen Psychiatry 1979;36:735-9.

${ }^{3}$ Reveley AM, Reveley MA, Clifford CA, Murray RM. Cerebral ventricular size in twins discordant for schizophrenia. Lancet 1982;i:540-2.

${ }^{4}$ Huber G. Pneumoencephalographische und Psychopathologische Bilder Bei Erdogen Psychosen. Berlin: Springer Verlag, 1957.

${ }^{5}$ Haug JO. Pneumoencephalographic studies in mental disease. Acta Psychiatr Scand 1962;38suppl:165.

${ }^{6}$ Asano N. Pneumoencephalographic study of schizophrenia. In: Mitsuda N, ed. Clinical Genetics in Psychiatry. Tokyo: Igaku-shoin, 1967:209-19.

${ }^{7}$ Brown R, Colter N, Corsellis JAN, et al. Brain weight and parahippocampal gyrus thickness are reduced and temporal horn area is increased in schizophrenia by com- 
parison with affective illness. Arch Gen Psychiatry 1985, (in press).

${ }^{8}$ Steiner RE, Bydder GM. Clinical nuclear magnetic resonance imaging. In: Dawson AM, Compston ND, Besser GM, eds. Recent Advances in Medicine. No 19. London: Churchill Livingstone, 1984.

${ }^{9}$ Macmillan LF, Crow TJ, Johnson AL, Johnstone EC. The Northwick Park Study of First Episodes of Schizophrenia. 3. The Short-Term Outcome. Br J Psychiatry 1985 (in press).

${ }^{10}$ Wing JK, Cooper JE, Sartorius N. The Measurement and Classification of Psychiatric Symptoms. London: Cambridge University Press, 1974.

${ }^{11}$ Johnstone EC, Crow TJ, Johnson AL, Macmillan JF. The Northwick Park Study of First Episodes of Schizophrenia. 1. Presentation of the Illness and Problems Relating to Admission. Br J Psychiatry 1985 (in press).
${ }^{12}$ Krawiecka M, Goldberg D, Vaughan M. A standardised psychiatric assessment for rating chronic psychotic patients. Acta Psychiatr Scand 1977;55:299-308.

${ }^{13}$ Cooper B. Social Class and Prognosis in Schizophrenia. Br J Prevent Soc Med 1961;15:17-41.

${ }^{14}$ Young IR, Bailes DR, Burl M. Initial clinical evaluation of a whole body NMR tomograph. J Comput Tomogr 1982;6:1-18.

${ }^{15}$ Young IR, Randell CP, Kaplan PW, James A, Bydder GM, Steiner RE. NMR imaging in white matter disease of the brain using spin echo sequences. $J$ Comput Assist Tomogr 1983;7:290-4.

${ }^{16}$ Bradley WG, Waluch V, Brant-Sawaelski M, Yadley RA, Wycoff RR. Patchy periventricular white matter lesions in the elderly. A common observation during NMR imaging. Non-invasive Medical Imaging 1984;i:35-41. 